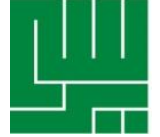

KATA KUNCI

KEYWORDS

ABSTRAK

ABSTRACT

\section{Hubungan antara Depresi dengan Kualitas Hidup pada Ibu Hamil Berisiko Tinggi}

\section{The Relationship Of Depression With Quality Of Life In Pregnant Women At High Risk}

\author{
Rizky Fauzy ${ }^{1} \&$ Endang Fourianalisyawati ${ }^{2}$ \\ Fakultas Psikologi Universitas YARSI \\ Jl. Letjen Suprapto Kav 13, Menara YARSI Lantai 6, Cempaka Putih, Jakarta Pusat. \\ fauzirizky110@gmail.com; endangfouriana@gmail.com
}

Depresi, kualitas hidup, ibu hamil berisiko tinggi

Depression, quality of life, high-risk pregnant women

Kehamilan risiko tinggi (risti) adalah suatu kehamilan yang memiliki ancaman lebih besar dari biasanya seperti terjadi penyakit atau kecacatan bahkan kematian sebelum maupun sesudah persalinan. Kondisi kehamilan dengan risiko membuat penderita lebih rentan mengalami gangguan psikologis salah satunya adalah depresi. Hal tersebut terjadi karena berbagai hal seperti, kekhawatiran akan keselamatan janin, ancaman kematian yang lebih besar dan keterbatasan dalam beraktivitas. Tantangan yang lebih besar saat menjalani kehamilan juga dapat mempengaruhi kualitas hidup yaitu, persepsi individu mengenai keberfungsian mereka dalam kehidupan. Salah satu faktor yang menyebabkan individu memiliki kualias hidup yang buruk yaitu ketika individu mengalami gangguan psikologis berupa depresi. Penelitian ini bertujuan untuk melihat hubungan depresi dengan kualitas hidup pada ibu hamil berisiko tinggi. Subjek dalam penelitian ini adalah 105 orang ibu hamil berisiko tinggi yang berada di Jakarta Timur. Penelitian ini menggunakan alat ukur Center for Epidemiologic Studies Depression Scale (CESD-R) dan World Health Organization Quality of Life-Bref (WHOQOL-BREF) yang sudah diadaptasi oleh peneliti. Uji hipotesis menunjukkan bahwa depresi berhubungan secara signifikan pada setiap dimensi kualitas hidup.

High risk pregnancy (risti) is a condition pregnancy with a greater threat than usual as the case of illness or disability and even death before and after childbirth. Condition of risk pregnancy making the patient more susceptible to psychological disorders one of which is depression. This happens for many reasons, such as concerns about the safety of the fetus, death threats are greater and limitations in activity. A greater challenge when undergoing pregnancy can also affect the quality of life, the individual's perception of their functioning in life. One of the factors that cause an individual has a poor quality of life that when people experience psychological disorders such as depression. This study aims to examine the 
relationship of depression with quality of life in pregnant women at high risk. Subjects in this study were 105 high-risk pregnant women who were in East Jakarta. This study uses a measuring instrumen Center for Epidemiologic Studies Depression Scale (CESD-R) and World Health Organization Quality of Life-Bref (WHOQOL-BREF) which has been adapted by researchers. The hypothesis suggests that depression is associated significantly in every dimension of quality of life.

\section{PENDAHULUAN}

Kehamilan merupakan suatu proses alamiah yang menyenangkan dan didambakan oleh setiap wanita, bukan hanya semata-mata untuk meneruskan keturunan, tetapi juga dapat melengkapi kesempurnaan sebagai seorang wanita (Primadewi, 2008). Ketika seorang wanita hamil, kondisi fisik sewaktu-waktu dapat berubah, salah satunya konidisk kehamilan yang memiliki risiko atau disebut dengan kehamilan berisiko tinggi (risti) (Kusmiyati, 2008). Kehamilan risiko tinggi (risti) adalah suatu kehamilan yang memiliki risiko lebih besar dari biasanya (baik bagi ibu maupun bayinya), dapat terjadi penyakit atau kecacatan bahkan kematian sebelum maupun sesudah persalinan. Kehamilan dengan risiko tinggi pada ibu hamil meliputi: umur ( terlalu muda yaitu kurang dari 20 tahun dan terlalu tua yaitu lebih dari 35 tahun ), jarak kurang dari 2 tahun, tinggi badan kurang dari $145 \mathrm{~cm}$, lingkar lengan atas kurang dari 23,5 cm, hemoglobin kurang dari 11 gr/dl, hamil lebih dari 4 kali, riwayat keluarga menderita penyakit kencing manis atau diabetes melitus, hipertensi dan riwayat cacat kongenital, kelainan bentuk tubuh, misalnya kelainan tulang belakang atau panggul (Azwar, 2008).

Kondisi kehamilan yang berisiko juga dapat mengakibatkan terganggunya kondisi psikologis. Hal yang cukup berbahaya ialah, ibu hamil berisiko rentan mengalami depresi. Hasil penelitian di Indonesia menunjukkan bahwa hampir $50 \%$ wanita hamil dengan risiko mengalami gejala depresi. Hasil serupa ditemukan dalam banyak survei dan studi di berbagai negara, yaitu sekitar 23\%-50\% ibu hamil berisiko mengalami gangguan psikologis, diantaranya adalah gangguan depresi. Hal tersebut dikarenakan perasaan yang didominasi oleh rasa cemas, resah dan takut terhadap kehamilan yang berisiko (Hawari, 2006). Hal yang menyebabkan ibu hamil berisiko tinggi mengalami depresi karena mereka memiliki karakteristik tersendiri yang dianggap berbahaya sehingga mereka memiliki tingkat kecemasan yang lebih tinggi terhadap keselamatan janin yang dikandung (Brandon \& Hymen, 2008).

Gangguan depresi yang dialami saat hamil juga dapat berpengaruh pada kondisi kesehatan bayi. Pada penelitian yang dilakukan pada ibu yang memiliki gejala depresi, didapatkan berat badan bayi ketika lahir menjadi rendah. Gejala depresi lebih banyak terjadi pada kelompok ibu yang melahirkan Berat Bayi Lahir Rendah (BBLR) dibandingkan dengan ibu yang melahirkan bayi dengan Berat Badan Lahir Normal (BBLN) (Hapisah, Dasuki, Probandari, 2010).

Masalah yang tidak dapat dianggap remeh pada kehamilan risiko tinggi adalah 
kematian yang mengancam untuk ibu dan juga janin. World Health Organization (WHO) mengatakan tahun 2010 Angka Kematian Ibu (AKI) di Amerika Serikat yaitu 17 per 100.000 kelahiran hidup, Afrika Utara 92 per 100.000, Asia Barat 68 per 100.000. Hasil penelitian Khan et al., (2006) dari lembaga WHO (World Health Organization) menyampaikan bahwa selain memilki kondisi penyulit saat hamil, kehamilan dengan risiko tinggi menyumbang angka kematian yang besar di berbagai negara, baik di Afrika, Amerika Latin, Karibia dan negara-negara Asia.

Kondisi-kondisi yang dialami ibu hamil risti dan ancaman kematian yang membayangi, berdampak pada kualitas hidup selama proses kehamilan yang disertai risiko (Akhyar, 2010). Dalam hal fisik, kehamilan risti memiliki penyulit pada masa kehamilan sehingga kesehatan ibu dan janin menjadi terancam. Begitu pula dengan kondisi psikologis, ibu hamil risti memiliki tingkat kekhawatiran yang lebih tinggi dikarenakan kondisi penyulit yang dialami.

Selain berdampak pada fisik dan psikologis kehamilan risti berdampak pada hubungan sosial ibu, salah satunya adalah mereka memiliki keterbatasan berinteraksi secara langsung dengan orang lain dikarenakan kondisi risti yang mengharuskan ibu lebih banyak meluangkan waktu untuk bed rest. Kehamilan risti juga berdampak pada lingkungan dimana ibu tinggal, salah satunya adalah kelayakan tempat tinggal yang mendukung agar kondisi ibu yang berisiko tidak semakin parah (Cauto et al., 2009).

Menurut The World Health Organization Quality of Life (WHOQOL) Group (Morrison \& Bennet, 2006) kualitas hidup didefinisikan sebagai persepsi individu mengenai posisi individu, yang hidup dalam konteks budaya dan sistem nilai dimana individu hidup, dan hubungannya terkait dengan tujuan, harapan, standar yang ditetapkan dan menjadi perhatian seseorang. Kualitas hidup ibu hamil risti dapat dilihat dari berbagai hal misalnya kesehatan fisik, kesejahteraan psikologis, hubungan sosial dan lingkugan (Elvina,2011)

Menurut hasil penelitian, wanita yang memiliki riwayat kehamilan berisiko, (seperti mengalami keguguran berulang lebih dari tiga kali, kelahiran premature, kematian pada bayi yang baru lahir) memiliki kualitas hidup yang buruk dibandingkan dengan yang tidak memiliki riwayat kehamilan berisiko. Selain kualitas hidup yang buruk, wanita yang memiliki riwayat berisiko menunjukkan gejala kecemasan, depresi dalam kehamilan berikutnya (Cauto, et al, 2009). Menurut hasil penelitian Fourianalistyawati \& Caninsti, (2014), terdapat 55 subjek degan kriteria hamil risiko tinggi di Jakarta, yang memiliki nilai kualitas hidup yang rendah sebanyak 21,8 \%, kategori sedang sebanyak $63,6 \%$ dan kategori tinggi sebanyak $14,5 \%$. Hal ini menunjukkan bahwa ibu hamil risiko tinggi yang memiliki kualitas hidup rendah lebih besar jumlahnya dari pada ibu hamil risti yang memiliki nilai kualitas hidup yang tinggi.

Penelitian di negara maju terus dilakukan untuk pengembangan pengetahuan sebagai upaya peningkatan kesejahteraan pada ibu hamil. Salah satu penelitian yang dilakukan di negara Spanyol. Nicholson et al., (2006) melakukan penelitian mengenai hubungan depresi dan kualitas hidup sehat pada kehamilan berisiko tinggi, dan didapatkan hasil yang signifikan. Wanita yang 
memiliki depresi pada kehamilan risti, memiliki kualitas hidup sehat yang rendah. Untuk mendapatkan kualitas hidup yang baik sangat terkait dengan pengaturan pola makan dan minum yang halal dan baik, keseimbangan beraktivitas dan beristirahat, olahraga dan ibadah. Apabila hal-hal tersebut dapat dipenuhi dengan cara yang tepat, maka akan lebih mendekati kehidupan yang sehat dan berkesinambungan.

Berdasarkan pemaparan diatas terkait dengan fenomena serta data-data yang didapatkan dari beberapa hasil penelitian, terdapat beberapa penelitian yang telah memaparkan tema terkait dengan depresi pada kehamilan, depresi pada kehamilan risiko tinggi, dan akibat dari terjadinya depresi pada kehamilan. Namun penelitian terkait dengan hubungan antara depresi dengan kualitas hidup pada ibu hamil risiko tinggi di Indonesia khusunya di Jakarta saat ini belum dapat ditemukan oleh peneliti.

Mengingat hal tersebut, maka peneliti merasa perlu untuk melakukan penelitian lebih lanjut tentang hubungan depresi dan kualitas ibu hamil risiko tinggi khusunya di Jakarta Timur. Pemilihan wilayah di Jakarta Timur karena, angka kematian pada ibu hamil di wilayah tersebut cukup tinggi. Data yang diterbitkan oleh Profil Kesehatan DKI Jakarta tahun 2012 menyebutkan bahwa terdapat 97 kematian pada ibu. Jumlah kematian ibu tertinggi terletak pada wilayah Jakarta Timur sebanyak 34 Jiwa, 23 kematian ibu di Jakarta Utara, 12 kematian ibu di Jakarta Pusat dan Jakarta Barat dan tidak ada kejadian kematian ibu di Kepulauan Seribu. Penyebab kematian yang terjadi di wilayah DKI Jarkarta ialah hipertensi, eklampsia, pendarahan yang disebabkan anemia, abortus dan peyebab lainnya. Beberapa penyebab di atas merupakan karakteristik dari kehamilan risiko tinggi (Dinas Kesehatan DKI Jakarta, 2012).

\section{Depresi}

Radloff (1977) mendefinisikan depresi sebagai:"symptoms which are a depressed mood, feeling so helplessness and hopelessness, feeling so guilt and worthlessness, loss of appetite, sleep disturbances, and psychomotor retardation". Jadi depresi berkaitan dengan gejala-gejala penurunan mood, perasaan tak berdaya dan tidak memiliki harapan, merasa bersalah dan tidak berharga, hilangnya nafsu makan, gangguan tidur dan hambatan psikomotor.

Menurut komponen dasar yang dikemukankan oleh Radloff (1977) kemudian setelah direvisi menjadi CESD$\mathrm{R}$ terdapat sembilan dimensi yang diperbaiki oleh Eaton et al., (2004) yaitu: (1) Kesedihan, yaitu suasana perasaan yang tidak menyenangkan pada diri individu; (2) Kehilangan minat yaitu kehilangan minat \& menarik diri dari semua aktifitas yang rutin dan menyenangkan; (3) Nafsu, yaitu hilangnya keinginan untuk makan pada diri individu; (4) Tidur, yaitu gangguan tidur dan kualitas tidur pada individu; (5) Berpikir dan konsentrasi yaitu kemampuan kognitif seperti berpikir, dan konsentrasi yang dimiliki individu; (6) Rasa bersalah dan tidak berharga, yaitu adanya rasa bersalah dan juga ketidakberhargaan dalam diri individu; (7) Kelelahan yaitu rasa lelah yang dimiliki oleh individu; Pergerakan, yaitu kemampuan pergerakan dan perpindahan dari satu tempat ke tempat lain; (9) Keinginan bunuh diri yaitu keinginan individu untuk mengakhiri hidupnya. 
Depresi merupakan salah satu diantara bentuk gangguan keseimbangan mood (suasana perasaan). Mood adalah kondisi perasaan yang terus ada yang mewarnai kehidupan psikologis individu. Perasaan sedih atau depresi bukanlah hal yang abnormal dalam konteks peristiwa atau situasi yang penuh tekanan. Namun orang dengan gangguan mood yang luar biasa parah atau berlangsung lama akan mengganggu kemampuan mereka untuk berfungsi secara normal (Semiun, 2006).

Perasaan-perasaan khawatir, cemas dan sedih bisa terjadi pada individu yang mengalami kehamilan dengan risiko tinggi. Menurut Azwar (2008), kehamilan dengan risiko tinggi ialah kehamilan yang memiliki risiko lebih besar dari biasanya (baik bagi ibu maupun bayinya), dapat menyebabkan terjadinya penyakit atau kecacatan bahkan kematian sebelum maupun sesudah persalinan.

\section{Kualitas Hidup}

Menurut WHOQOL Group (dalam Morrison \& Bennet, 2006) kualitas hidup didefinisikan sebagai persepsi individu mengenai posisi individu, yang hidup dalam konteks budaya dan sistem nilai dimana individu hidup, dan hubungannya terkait dengan tujuan, harapan, standar yang ditetapkan dan menjadi perhatian seseorang.

Berdasarkan definisi kualitas hidup yang dikemukakan oleh WHOQOL Group dalam (Morrison \& Bennet, 2006), penilaian ataupun persepsi individu terhadap kualitas hidup ditentukan oleh berbagai hal yaitu gender \& jenis kelamin, usia, pendidikan, pekerjaan, status pernikahan, penhgasilan, hubungan dengan orang lain, dan budaya.

Mengalami kehamilan yang berisiko merupakan suatu keadaan dimana seorang ibu hamil harus berjuang melawan risiko yang dialami dan bertahan atas keterbatasan yang dimiliki. Penderitaan kehamilan yang berisiko dapat menimbulkan rasa putus asa bahkan depresi. Apabila ibu hamil berisiko memiliki kondisi psikologis yang kurang baik atau mengalami depresi, maka akan berdampak pada kemampuan mereka untuk berfungsi secara normal. Jika kondisi tersebut terus berlangsung maka hal ini sangat berbahaya untuk keberlangsungan hidup ibu dan bayi. Beberapa kondisi yang dialami oleh ibu hamil berisiko akan berdampak pada pola kehidupannya. Hal tersebut dapat menjadi penentu kualitas hidup ibu hamil berisiko. Kualitas hidup sendiri menjadi ukuran standar kesehatan terutama untuk beberapa orang dengan penyakit kronis, fungsional, psikologis dan penyakit yang tidak bisa disembuhkan (Preedy \& Watson, 2010).

Keadaan semacam itu akan mempengaruhi kualitas hidup ibu hamil berisiko tinggi. Dalam penelitian ini ada empat aspek kualitas hidup ibu hamil bersiko tinggi seperti yang dipaparkan oleh (Morrison \& Bennet, 2006) yaitu aspek kesehatan fisik, aspek kesejahteraan psikologis, aspek hubungan sosial, dan aspek hubungan dengan lingkungan.

\section{METODE PENELITIAN}

Penelitian ini menggunakan desain penelitian korelasional, karena bertujuan untuk mengetahui sejauh mana satu variabel berkaitan dengan satu atau lebih variabel yang lain (Azwar, 2012). Fokus dari penelitian ini adalah untuk mengetahui hubungan depresi dengan kualitas hidup pada ibu hamil risiko tinggi.

Variabel bebas dalam penelitian ini adalah depresi, dimana dalam penelitian ini skor resiliensi diperoleh menggunakan 
skala skala adaptasi Center for Epidemiologic Studies Depression Scale (CESD-R) menurut Eaton et al. (2004). Skor yang lebih tinggi mengindikasikan adanya gejala depresi pada subjek. Begitu pula sebaliknya, semakin rendah skor yang diperoleh maka akan dapat dikatakan bahwa subjek tidak terindikasi depresi.

Variabel terikat dalam penelitian ini adalah kualitas hidup, skor kualitas hidup ditunjukkan oleh skor dari setiap dimensi kualitas hidup menggunakan skala adaptasi World Health Organization Quality of Life-Bref (WHOQOL-BREF) menurut WHO. Skor setiap dimensi didapatkan dari respon individu dalam mempersepsikan setiap aitem pada dimensi tersebut (dalam Morrison \& Bennet, 2006). Semakin tinggi skor pada tiap dimensi kualitas hidup, maka semakin tinggi kualitas hidup pada tiap dimensi. Semakin rendah skor pada tiap dimensi kualitas hidup, maka semakin rendah kualitas hidup pada setiap dimensi.

Sampel yang digunakan dalam penelitian ini adalah 105 partisipan yang mewakili para ibu risti yang menjadi pasien di beberapa RSIA yang berlokasi di wilayah Jakarta Timur. Sampel diperoleh dengan menggunakan teknik non probability sampling, dimana semua anggota populasi tidak mempunyai kesempatan yang sama untuk menjadi subjek penelitian. Adapun teknik pengambilan sampel dengan menggunakan teknik purposive sampling. Karakteristik spesifik sampel penelitian adalah ibu hamil yang termasuk dalam kehamilan risiko tinggi dan berdomisili di wilayah Jakarta Timur. Karakteristik kehamilan risiko tinggi pada penelitian ini sesuai dengan karakteristik yang dijelaskan oleh Rochjati (2007) yaitu, (1) Usia (Kurang dari 16 tahun atau lebih dari 35 tahun); (2) Ibu hamil dengan usia anak terkecil diatas 5 tahun; (3) Tinggi badan kurang dari 145 cm; (4) Pengalaman kehamilan di masa yang lalu dan saati ini yang dibedakan dari faktor kehamilan, kelahiran dan faktor janin)

\section{ANALISI DAN HASIL}

Berdasarkan hasil uji coba normalitas, didapatkan skor normalitas depresi sebesar $1.989(\mathrm{p}=0.001<0.05)$ dan kualitas hidup sebesar 0.864 ( $\mathrm{p}=$ $0.252>0.05$ ). Hal tersebut memiliki arti bahwa variabel depresi tidak berdistribusi normal. Oleh karena itu, data penelitian ini dapat dianalisa dengan menggunakan metode statistitik non parametrik, Spearman Correlation.

Hasil penelitian menunjukkan bahwa skor total depresi dengan skor setiap dimensi dari kualitas hidup WHOQOLBREF. Hasil penelititian ini sesuai dengan pendapat Semiun (2006) bahwa seseorang yang mengalami depresi akan terganggu kemampuan mereka untuk berfungsi secara normal sehingga kualitas hidup orang yang mengalami depresi berada pada posisi yang tidak seimbang. Hasil penelitian ini juga sejalan dengan penelitian sebelumnya yang dilakukan Nicholson, et al (2006), bahwa ibu hamil berisiko tinggi yang mengalami depresi akan mempengaruhi kualitas hidup selama masa kehamilan.

Skor depresi juga memiliki korelasi negatif yang signifikan dengan setiap dimensi kualitas hidup WHOQOL-BREF dengan penjabaran sebagai berikut:

- Depresi memiliki korelasi negatif yang signifikan dengan dimensi kesehatan fisik kualitas hidup sebesar $r=-0.614$ $(\mathrm{p}=0.00<0.01)$. Hal ini berarti terdapat hubungan yang kuat antara depresi dengan kualitas hidup, semakin tinggi tingkat depresi individu maka akan semakin rendah 
persepsi individu terhadap kualitas hidup pada dimensi kesehatan fisik. Sundari (2005) menyatakan terdapat hubungan antara kesehatan fisik dan mental. Individu yang menderita penyakit fisik cenderung menunjukkan kondisi mental yang negatif seperti: mudah tersingung, pesimis sehingga memperlambat prorses penyembuhan.

- Depresi dengan dimensi kesejahteraan psikologis memiliki korelasi negatif yang signifikan sebesar $r=-0.644(\mathrm{p}$ $=0.00<0.01)$. Hal ini juga menunjukkan terdapat hubungan yang kuat antara depresi dengan persepsi individu terhadap tingkat kualitas hidup aspek kesejahteraan psikologisnya. Semakin tinggi tingkat depresi individu maka akan semakin rendah persepsi individu terhadap tingkat kualitas hidup aspek kesejahteraan psikologisnya. Hal ini sejalan dengan penelitian yang dilakuk oleh Hendrik (2013) yang menunjukkan ketika individu mengalami depresi maka secara langsung kondisi psikologis terganggu.

- Depresi dan dimensi hubungan sosial memiliki hubungan negatif sebesar $r$ $0.458(\mathrm{p}=0.00<0.01)$. Hubungan ini bersifat negatif sehingga semakin tinggi skor depresi individu, semakin rendah persepsi individu terhadap tingkat kualitas hidup aspek hubungan sosialnya. Koefisien korelasi $r=-$ 0.458 merupakan tingkat hubungan yang sedang. Hal ini sejalan dengan hasil penelitian Prasetyo (2008) yang menunjukkan bahwa significant others dapat menjadi sumber motivasi, menimbulkan ketenangan batin dan perasaan senang pada ibu hamil. Sehingga meskipun ibu hamil berisiko mengalami kondisi yang berbahaya tetap dapat berfugsi dalam kehidupan sosial karena mendapatkan dukungan sosial dari lingkungannya (Dagun, 2002).
- Depresi memiliki korelasi negatif yang signifikan dengan dimensi lingkungan sebesar $r=-0.465(\mathrm{p}=0.00<\mathrm{p} 0.01)$. Hubungan ini bersifat negatif sehingga semakin tinggi tingkat depresi individu, semakin rendah persepsi individu terhadap tingkat kualitas hidup aspek lingkungan hidup. Koefisien korelasi $r=\quad-0.465$ merupakan tingkat hubungan yang sedang.

\section{SIMPULAN}

Hasil penelitian menunjukkan adanya hubungan yang signifikan dan bernilai negatif antara depresi dengan seluruh dimensi kualitas hidup. Hubungan ini bersifat negatif dengan artian semakin tinggi skor depresi subjek, maka semakin rendah persepsi subjek terhadap kualitas hidup.

\section{SARAN}

Saran praktis yang dapat diberikan berdasarkan hasil penelitian ini, adalah:

- Depresi ditemukan pada ibu hamil berisiko tinggi, sehingga hal ini seharusnya menjadi perhatian yang lebih bagi para instansi kesehatan, ibu hamil yang memiliki risiko kehamilan, keluarga dan bagi pemerintah.

- Bagi ibu hamil bersiko tinggi hendaknya melakukan pemeriksaan psikologis selain dari pemeriksaan fisik. Keadaan depresi yang dialami pada ibu hamil berisiko tinggi apabila tidak ditangani oleh ahli profesional dapat membahayakan keselamatan ibu dan janin.

- Bagi keluarga seperti suami, dan sanak saudara hendaknya selalu mendampingi ibu hamil yang memiliki risiko pada kehamilan. Kondisi kehamilan yang berisiko telah memiliki penyulit secara fisik sehingga mereka sangat memerlukan dukungan keluarga agar kehamilan berjalan dengan baik. 
- Bagi instansi kesehatan seperti dokter, hendaknya bekerja sama dengan ahli psikologis seperti psikolog ataupun psikiater agar ibu hamil berisiko tinggi mendapatkan intervensi psikologis yang seesuai agar kehamilan berjalan dengan lancar.

\section{DAFTAR PUSTAKA}

Akhyar, Y. (2010). Deteksi Ibu Hamil Resiko Tinggi (Bumil Risti) Di Posyandu. Diperolehi pada 1 September 2014 dari pada http://yayanakhyar.wordpress.com/201 0/05/11/deteksi-ibu-hamil-resikotinggi-bumil-risti-di-posyandu/.

Azwar, A. (2008). Pengantar epidemiologi. Jakarta: Binarupa Aksara.

Azwar, S. (2012). Penyusunan Skala Psikologi. Yogyakarta: Pustaka Belajar.

Brandon, A. R. \& Hymen, L. S. (2008). Depression is More Common in Women With High Risk Pregnancies. Prenatal Depression in Women Hospitaliazed for Obstetric Risk. Jclin Psychiatry. (27).

Cauto, E. R., Cauto, E., Vian, B., Gregorio, Z., Nomura, M. L., Zaccaria, R., \& Junior, R. P. (2009). Quality of life depression and anxiety among pregnant women with previous adverse pregnancy outcomes. 127 (4), 185.

Dinas Kesehatan Provinsi Jakarta. (2012). Profil Kesehatan Provinsi Jakarta tahun 2012. Jakarta: Dinas Kesehatan Provinsi Jakarta.

Eaton, W., Smith, C., Ybarra, M., Muntaher, C., Tien, A. (2004). Center for Epidemiologic Studies Depression Scale: Review and Revission (CESD and CESD-R). In ME Maurish (Ed). The Use of Psycological $n$ Testing for Treatment Planning and Outcomes Assesment. (3), 363-377.

Fourianalistyawati, E., \& Canisti, Riselligia. (2014). Kualitas Hidup pada Ibu dengan Kehamilan Risiko Tinggi.
Prosiding Konferensi Nasional II Psikologi Kesehatan. Jilid I.

Irma, N. (2012). Hubungan penyakit penyerta kehamilan dan tingkat pendapatan selama kehamilan dengan tingkatan depresi pada ibu hamil trimester III di poliklinik kebidanan dan kandungan RSUP Fatmawati 2010. Ilmu Kedokteran dan Kesehatan. 70, (28).

Hapisah., Dasuki, D., \& Probandari, Y, S. (2010). Depressive Symptom pada Ibu Hamil dan Bayi Berat Lair Rendah. Berita Kedokteran Masyarakat. 26, (2).

Hawari, D. (2006). Manajemen stress cemas dan depresi. Jakarta: Fakultas Kedokteran Indonesia.

Jannah, N. (2012). Buku Ajar Asuhan Kebidanan - Kehamilan. Yogyakarta: Andi Lily, Yuliakhah, (2008). Kehamilan. Jakarta: EGC.

Khan, K. S., Wojdyla, D., Say, L., Gulmezoglu, A. M., Look, P. (2006). WHO analysis of causes of maternal death: a sustematic review. Lancet. (367), 1066-74.

Kusmiyati. (2008). Perawatan Ibu Hamil. Yogyakarta : Fitra Mya.

Joyce, M. B. \& Jacobs, E. M. (1992). Luckman \& Sorensen's Medical surgical Nursing: A Psychophysiologic Approach. Philadelphia: W.b Saunder Company.

Morrison, V., \& Bennet, P. (2006). An Introduction to Health Psychology. Edinburgh: Pearson Prentice Hall.

Nicholson, W. K., Setse, R., Hill-Briggs, F., Cooper, L. A., Srobino, D., \& Neil. (2006). Depressive Symptom and Health-Related Quality of Life in Early Pregnancy. American College of Obstetricians and Gynecology. (4), 107.

Preedy ,V.R., and Watson,R.R. (2010) .Handbook of Desease Burdens and Quality of Life Measure. Diperolehi pada 22 Juli 2015 dari pada www.http://library.nu/search?q=Qualit y\%20of\%20life\&page. 
Primadewi, R. (2008). Rahasia kehamilan. Jakarta: Shira Media.

Radlooff, L. S. (1977). The CES-D Scale: A Self Report Depression Scale For Research in General Population. Applied Psychology Measurement. 1 (63), 385-401.

Rochjati, P. (2007). Skrining Antenatal Pada Ibu Hamil. Surabaya: Air Langga University press.
Semiun, Yustinus, (2006), Kesehatan Mental 3, Yogyakarta: Penerbit Kanisius.

Sujiyanti. (2009). Asuhan Patologi Kebidanan. Jakarta: Nuha Medika.

Yogi, E. D. (2014). Hubungan Antara Usia Dengan Preeklampsia Pada Ibu Hamil Di POLI KIA RSUD Kefamena Kabupaten Timor Tengah Utara. Jurnal Delima Harapan. 3, (2), 10-19. 